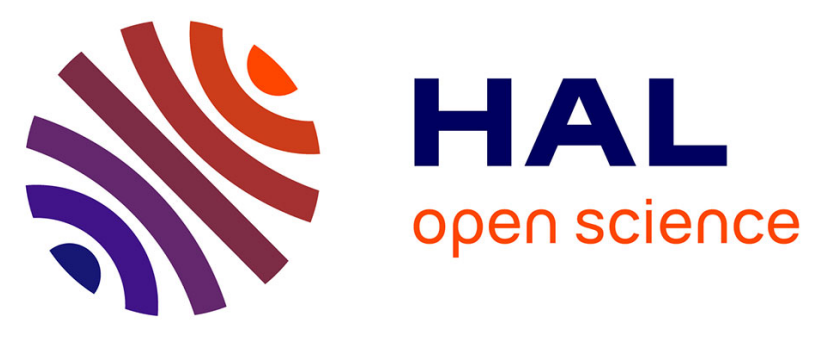

\title{
From Bottom-up Insights to Feature Ideas: A Case Study into the Office Environments of Older Knowledge Workers
}

\author{
Valentin Gattol, Jan Bobeth, Kathrin Röderer, Sebastian Egger, Georg Regal, \\ Ulrich Lehner, Manfred Tscheligi
}

\section{To cite this version:}

Valentin Gattol, Jan Bobeth, Kathrin Röderer, Sebastian Egger, Georg Regal, et al.. From Bottom-up Insights to Feature Ideas: A Case Study into the Office Environments of Older Knowledge Workers. 4th IFIP 13.6 Working Conference on Human Work Interaction Design (HWID), Jun 2015, London, United Kingdom. pp.83-96, 10.1007/978-3-319-27048-7_6 . hal-01371789

\section{HAL Id: hal-01371789 \\ https://hal.inria.fr/hal-01371789}

Submitted on 9 Nov 2016

HAL is a multi-disciplinary open access archive for the deposit and dissemination of scientific research documents, whether they are published or not. The documents may come from teaching and research institutions in France or abroad, or from public or private research centers.
L'archive ouverte pluridisciplinaire HAL, est destinée au dépôt et à la diffusion de documents scientifiques de niveau recherche, publiés ou non, émanant des établissements d'enseignement et de recherche français ou étrangers, des laboratoires publics ou privés. 


\title{
From Bottom-up Insights to Feature Ideas: A Case Study into the Office Environments of Older Knowledge Workers
}

\author{
Valentin Gattol, Jan Bobeth, Kathrin Röderer, Sebastian Egger, Georg Regal, Ulrich \\ Lehner, Manfred Tscheligi \\ AIT Austrian Institute of Technology GmbH \\ Innovation Systems Department, Technology Experience \\ Giefinggasse 2, 1210 Vienna, Austria \\ \{valentin.gattol, jan.bobeth, kathrin.roederer, \\ sebastian.egger, georg.regal, ulrich.lehner, \\ manfred.tscheligi\}@ait.ac.at
}

\begin{abstract}
Given recent demographic changes, adapting the office environments of older knowledge workers to their needs has become increasingly important in supporting an extension of working life. In this paper, we present a case study research of older knowledge workers in Romania, with the goal of gaining bottom-up insights that support the ideation, design, and development of features for a smart work environment. Utilizing a multi-method approach, we combine (1) contextual interviews and observations, (2) an analysis of needs and frictions for deriving insights, (3) an ideation workshop for eliciting potential features, (4) an online survey among experts for evaluating the final feature ideas, and (5) early stage prototyping of selected feature ideas. Following this comprehensive yet efficient approach, we were able to gain a rich understanding of the work realities and contexts of older knowledge workers and to transform that understanding into a concrete set of prioritized feature ideas.
\end{abstract}

Keywords: Knowledge workers; older adults; requirements analysis; multiple methods; contextual inquiries; needs-frictions analysis; NUF prioritization

\section{Introduction}

Within the European Union labor market participation rates currently reduce sharply along with age: while participation is high for the age group of 50-54 years $(75.5 \%)$, it drops noticeably for the age groups of 55-59 years (61.5\%) and 60-64 years (30.5\%) [1]. The OECD predicts that by the year 2050 the number of retired persons aged 50 and above will surpass the number of active persons in the workforce in Europe [2]. Given these demographic changes, policies geared towards motivating older persons to work longer have become more and more important. From a company perspective, older employees hold important knowledge and know-how, have high quality standards in their work, and are typically very loyal and dedicated to their

adfa, p. 1, 2011.

(C) Springer-Verlag Berlin Heidelberg 2011 
organizations [3]. Moreover, positive effects on productivity have been reported for age-diverse teams, with performances of both younger and older team members being significantly higher compared to less age-diverse teams [4]. Thus, the challenge is how we can support an extension in working life. On the one hand new policies are needed that strike the right balance between older employees' rights and interests and in increasing their employability [5]; on the other hand, efforts are needed that put a clear focus on innovation in the immediate environment of older workers.

In the present research we focus on the latter by means of a case study into the work environments of older knowledge workers in Romania. Older adults are a heterogeneous group with very different needs depending on physical, cognitive, and social constitution [6]. Also, experience with computers may vary greatly within this group and influence both the effectiveness and efficiency of using computers [7]. For this reason, it is crucial to provide tailored technology support that addresses the real needs of older knowledge workers. The case study presented in this chapter was part of a larger project, following the vision of developing a smart work environment that supports "a prolonged, productive and satisfactory involvement of older employees in working life" [8]. The aim of the case study was to provide feature ideas as input for the technical specification of a smart work environment. We followed a multi-method approach, combining (1) contextual interviews and observations for mapping the workplace environment, (2) an analysis of needs and frictions for deriving insights, (3) an ideation workshop for generating feature ideas, (4) an online survey among experts for prioritizing the feature ideas, and (5) early stage prototyping of selected feature ideas. As a result of this multi-method approach, we were able to gain a rich understanding of the work realities of older knowledge workers and to transform that understanding into a set of prioritized feature ideas. Such a list of feature ideas can serve as a valuable reference in the development of smart workplace solutions and offer crucial guidance on which features to select for further development and prototyping.

Our main contribution is an elaborate description of our comprehensive and efficient multi-method approach along with the results we obtained with this approach. We are confident that this approach will serve as a helpful tool for designers of smart workplace solutions.

The remainder of this chapter is structured as follows: in section 2, background and related work, we discuss current workplace trends in today's knowledge-based economies and different approaches in the goal-oriented design of smart work technologies; in section 3 we give a detailed account of the different phases in the multimethod approach; in section 4 we present the results of the case study that were obtained with this approach; and finally, in section 5, discussion and conclusion, we reflect on our experiences with the approach as a tool for informing the development of smart work place solutions. 


\section{Background and Related Work}

In recent years, daily work in our increasingly knowledge-based economy is demanding a high degree of flexibility and adaptability [9] in order to perform tasks anytime and anywhere [10]. Within this context, smart work approaches as alternative ways of organizing work supported by technology have emerged. One indication for this trend is the already widespread use of mobile devices in business contexts, which blurs the boundary between work and personal life by enabling people to complete work tasks when at home or on the go [11]. Many of today's knowledge workers embrace this trend, as it allows them to more flexibly allocate their time between work and personal life; yet, others are skeptical of the new technological possibilities, fearing that it may lead to an expectation of round-the-clock availability, as expressed in today's knowledge workers increasingly felt obligation to answer phone calls or check emails outside of regular office hours. Especially for the latter group, this can lead to increased stress levels and an off-kilter work-life balance [9]. Smart work technology has the potential to alleviate some of these negative impacts on work-life balance by supporting employees with tailored solutions that are better aligned with their particular goals and working style. Greene [12], for example, distinguishes four knowledge worker types with different goals and working styles: the anchor, who represents the traditional sedentary office worker at the desk; the connector, who spends most his/her time in meetings away from his/her desk; the gatherer, who mainly operates outside the office, for example, networking with clients and customers; and the navigator, who is rarely present at the office, working more independently and globally. The goal-oriented development of smart technologies thus requires a deeper understanding of workers' tasks and needs, in particular the special needs of older employees who cannot as easily adapt to new technologies as younger employees. Without such considerations, the adoption of smart work technologies remains rather low [10].

There are different approaches towards the goal-oriented design of supportive smart work technology. One approach is Human Work Interaction Design (HWID), a multidisciplinary framework combining work analysis (e.g., cognitive work analysis [9]) and interaction design, to promote a better understanding of the relationships between humans and work domain contents and the interaction during their tasks [13]. Another promising approach is Contextual Design [14]. According to this approach, great feature ideas evolve from the synthesis of a designer's detailed understanding of the users' needs (through direct involvement in data collection and interpretation) and his or her own in-depth understanding of the technological possibilities. This approach requires designers to visit the companies, in order to understand the workers' tasks and overall organizational processes, before technologies are customized for the company [15]. Visiting, in this case, means to apply some form of ethnographic research method, such as observations [16], contextual inquiries [14], design ethnography [17], or co-realization [18].

The many benefits of ethnographic research in the domain of computer supported collaborative work are reflected in the work by Blomberg and Karasti [19]. Design ethnography, for example, is based on the idea that observing and designing should not be strictly separated. In other words, the design process should not be limited to 
working in the reclusive environment of a design studio but experiment with design interventions on site and on the spot [20]. Similarly, co-realization emphasizes the need for a long-term engagement between designers and users, as the full implications of new technology for work practices can only be revealed in and through the system's subsequent use [18].

Given that many ethnographic approaches require considerable efforts in time and resources, we position our multi-method approach as a comprehensive yet efficient alternative to study the work realities and contexts of older knowledge workers. A key benefit of our approach is that it leads to a concrete set of prioritized feature ideas based on the involvement of relevant stakeholders. Designers and developers may consult such a list in selecting the most promising features for further development and prototyping.

\section{Multi-Method Approach}

In line with the overall goal of providing feature ideas as input for the technical specification of a smart work environment for older people, we followed a multi-method approach as depicted in Figure 1.

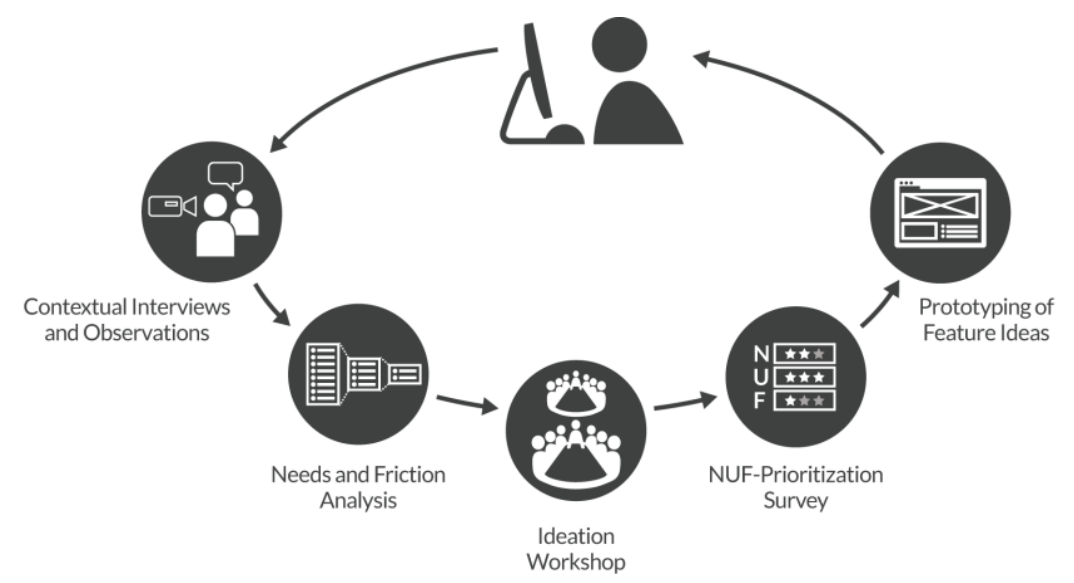

Figure 1. Overview of the phases in the multi-method approach

Within the first phase (see section 3.1), we aimed at gaining bottom-up insights into the work environments of older knowledge workers. Inspired by ethnographic approaches (see section 2), we analyzed the work environment as a whole, utilizing a combination of semi-structured interviews and observations at the workplace. The goal of the second phase (see section 3.2), was to identify needs and frictions from the interview transcripts and observation reports, which were then combined to insights. The goal of the third phase (see section 3.3), was to derive feature ideas based on these insights by conducting an ideation workshop. The goal of the fourth phase (see section 3.4), was to prioritize these feature ideas in an online survey among experts. Finally, the goal of the fifth phase (see section 3.5), was to develop selected feature 
ideas into prototypes to communicate the overall concept and to gather feedback at an early stage.

\subsection{Contextual Interviews and Observations}

Participants and Setting. Older knowledge workers (aged 50 years and above) are a heterogeneous group, characterized by different needs depending on physical, cognitive, and social constitution [6]. For the present study we focused on a subset of that group: knowledge workers who use computers on a daily basis and spend most of their time in the office (cf. with the Anchor and Connector working types described by Greene [12]). A convenience sample of eight older knowledge workers (two women) was drawn to take part in the contextual interviews and observations. The mean age was 55 years $(S D=3.93)$. The participants were recruited from two small IT companies in Bucharest that worked in hardware and software engineering in the domain of fiscal accounting. All participants were frequent users of smartphones, tablets, and laptops. The interviews and observations took place directly at the participants' workplace (see Fig. 2 below) and lasted for 60-90 minutes.
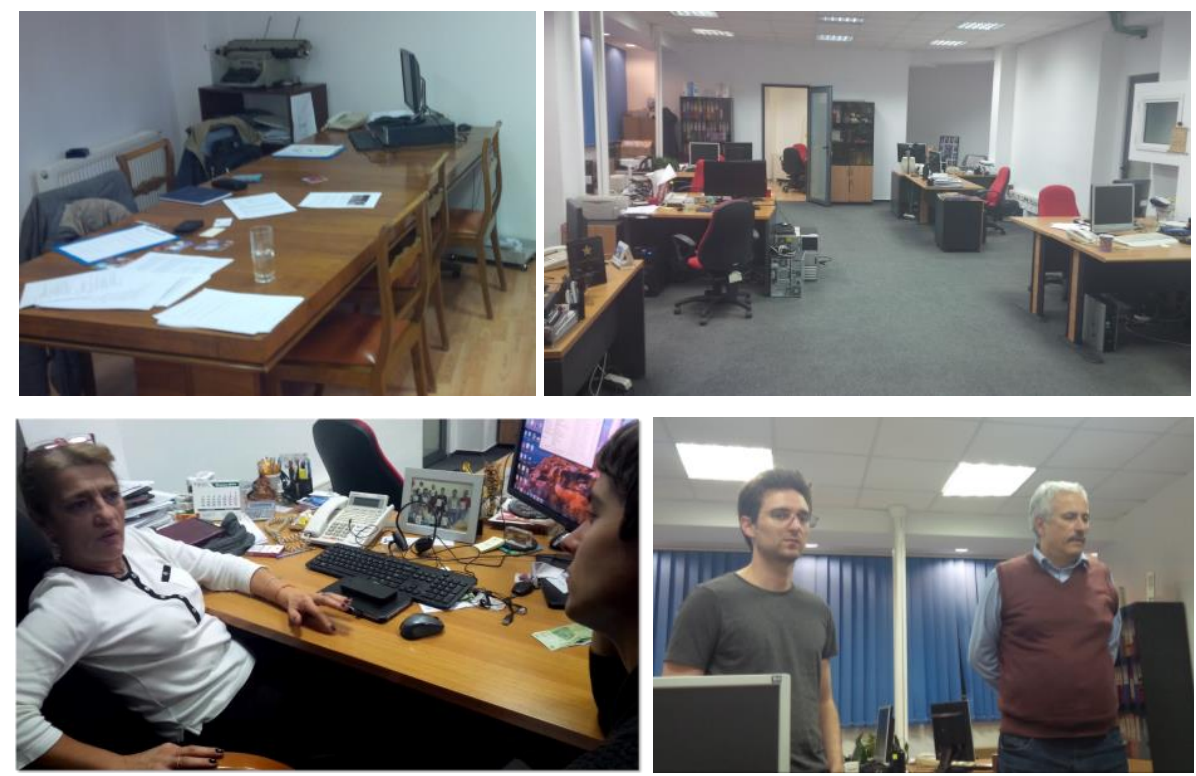

Figure 2. Study settings (clockwise from top left): (a) table for briefing participants, (b) open plan office area, (c) researcher and interpreter on site, (d) participant at her desk.

Procedure. Each session started with an informal conversation and the participant signing an informed consent document (see the setting in Figure 2a). Afterwards, we started recording with a Blackberry Z10 smartphone and proceeded with the contextual interviews and observations. The choice for using an unobtrusive smartphone 
camera rather than a professional camera was made deliberately, so that participants would not feel intimated. We followed the participants through the office to their workplaces (see Figure 2b) and encouraged them to present their work environment and typical tasks (see Figure 2d).

In line with the open character of our approach, we relied on a loose structure ensuring that participants still had enough leeway to act and speak spontaneously. Behavioral prompts (e.g., "Can you show us around your desk?") and follow-up questions (e.g., "Why do you prefer to take down appointments in a physical calendar?") were used to direct the attention to specific aspects. The contextual interviews and observations were conducted by two researchers with backgrounds in design and psychology. They were supported by a local interpreter who was crucial in overcoming cultural barriers, building rapport, and generally ensuring proper translation (see Figure $2 \mathrm{c}$ on the right). The researchers spoke English, the participants answered either in English or Romanian.

\subsection{From Needs and Frictions to Insights}

Data Preparation. More than 10 hours of video material was transcribed using the open source software easytranscript ${ }^{1}$. For those participants that answered in Romanian, only the English translations were transcribed. All names were anonymized.

Data Analysis. The goal of the analysis was to identify needs and frictions from the interview transcripts and observation reports, which were then combined to insights. For our purposes, we defined needs as something required in the execution of work, frictions as a certain issue that stands in the way of satisfying a need, and insights as an intuitive grasp of a need-friction situation (e.g., 'I need to meet objectives but sometimes I forget them.'). The analysis of the data involved two steps:

Step 1: Reading the transcripts, highlighting relevant utterances and observations, and categorizing them to themes (i.e., certain recurring patterns). For example, "staying in touch with distant colleagues" and "being stressed by the daily email load", would both be coded to belong to the theme Communication. The themes (see Tab. 1) structured the process of identifying the needs and frictions.

Step 2: After categorizing the relevant utterances and observations to themes, we identified underlying needs and frictions. Insights were formed by combining a specific need with a specific friction and formulated from the user's perspective (e.g., 'I need to communicate via email but I cannot handle the high email load'). In some cases, more than one insight could be identified for a specific need due to several frictions for the same need.

\footnotetext{
${ }^{1}$ http://www.e-werkzeug.eu/index.php/en/
} 


\subsection{Deriving Feature Ideas in an Ideation Workshop}

Participants of the Ideation Workshop. In order to generate a wide range of ideas we involved 15 professionals with backgrounds in software engineering, wireless communications, user experience design, marketing, psychological evaluation, sociological research, serious gaming, eLearning and telemedicine.

Procedure. For having a structured yet flexible way of brainstorming, we slightly adapted the World Café method [21] by using insights of the needs-frictions analysis as input for deriving feature ideas. Thus, we formulated the overall question as: considering these insights, which concrete feature would be helpful for users belonging to the target group of older knowledge workers?

We prepared four tables, each equipped with post-its, markers, and 9-10 insights. Each table was moderated by a host who stayed at the same table and took notes of the discussion. The other participants switched tables after each round (4 rounds in total). One round lasted for 20 minutes and always followed the same procedure: (1) Introduction: the host read out the insights and summarized the ideas discussed in the previous round; (2) Brain writing: each participant was given five minutes to write down as many ideas as possible; (3) Discussion: at each table participants discussed and developed feature ideas. At the end of the fourth round, the hosts consolidated the features ideas.

\subsection{Prioritizing Feature Ideas in an Online Survey}

Respondents. The goal of the fourth phase was to prioritize the feature ideas that resulted from the ideation workshop. For this purpose, the participants of the ideation workshop were asked to fill in an online survey. The prioritization was not part of the ideation workshop, as we wanted each expert to evaluate the ideas individually with no time pressure and unaffected by groupthink. We received 10 completed surveys.

Survey Design and Procedure. The survey relied on a simple design introducing each feature idea by its name and a short description, along with the insights from the needs-frictions analysis. The respondents' task was to score each feature on the three dimensions newness, usefulness, and feasibility (following the NUF approach, [22]). For each of the dimensions, respondents assigned any number of points ranging from 1 ('not new/useful/feasible at all') to 10 ('very new/useful/feasible'). Moreover, respondents were given the opportunity to leave comments in a text box for each feature. The survey was designed to take about 30-60 minutes to complete.

Data Analysis. The goal of the NUF is to arrive at an overall index score per feature. First, a total score per feature was calculated across the dimensions of newness, usefulness, and feasibility. Second, means and standard deviations were calculated across respondents in order to generate a rank-ordered list of the feature ideas (see Tab. 2 for the 10 highest ranked feature ideas). 


\subsection{Prototyping of Feature Ideas}

Scenarios. The goal of the fifth phase of the multi-method approach was to develop selected feature ideas into early stage prototypes. The first step in this process involved developing (use) scenarios. Scenarios describe a person, the person's goals and the steps the person takes to achieve these goals with the proposed system (cf. [23]). Using scenarios in an early stage of the design and development process provides a basic and shared understanding of the overall concept for the different stakeholders (cf. [24]).

Mockups. The second step in the prototyping process involved developing mockups based on the scenarios. For this we combined two of the highest-ranked feature ideas - the Private Digital Noteboard and the Digital Paper Calendar (see Tab. 2) - and developed them into a mockup utilizing off-the-shelf hardware (i.e., in our case a tablet, a smartphone and a paper calendar). Generally, mockups differ in fidelity along three dimensions: role, look and feel, and implementation (cf. [25]). We developed our mockup to the level of a medium-fidelity prototype covering the first two dimensions: role (i.e., functionality) and look and feel (i.e., size, form factor, overall design).

\section{$4 \quad$ Results}

Our comprehensive multi-method approach (see Fig. 1) allowed for gaining bottomup insights into the work realities of our target group, which were then used to generate feature ideas for a smart work environment, and to develop an example scenario and a mockup based on a combination of two highly-ranked feature ideas. In this section, we present the results we obtained from our approach.

Themes and Insights. In Table 1 we provide two examples of insights for each theme that resulted from a needs-frictions analysis of the contextual interview and observation transcripts. While some insights left room for creative ideas, other insights were so straightforward to suggest an easy solution (e.g., 'I need to write proper Romanian but the default English keyboards come without diacritics.') or so general that smart workplace solutions cannot help (e.g., 'I don't want to work at home but sometimes I have to.').

Table 1. Themes and Insights

\begin{tabular}{lrl}
\hline Themes & $\#$ & Insights (examples) \\
\hline Task & i1 & $\begin{array}{l}\text { I need to keep track of open tasks but carrying them over (e.g., from my } \\
\text { Manage- }\end{array}$ \\
$\begin{array}{l}\text { agenda to Outlook) takes effort. } \\
\text { ment }\end{array}$ & i2 $\begin{array}{l}\text { I need to meet objectives but sometimes I forget them ("Out of sight, out of } \\
\text { mind"). }\end{array}$ \\
$\begin{array}{l}\text { Commu- } \\
\text { nication }\end{array}$ & i3 & $\begin{array}{l}\text { I want to be able to send instant messages to both private and business con- } \\
\text { tacts but without mixing contacts. }\end{array}$
\end{tabular}


i4 I need to communicate via email but I cannot handle the high email load.

Collabora- i5 I need to solve bigger and complex problems but effective collaboration is tion difficult when people have different backgrounds/expertise.

i6 I need to share information digitally but there is no efficient way of digitizing hand-written information.

Mind \& $\quad$ i7 I want to train my mind but I don't know how to do it effectively ("To train

Body my mind I'm reading, solving crosswords, and checking Facebook").

i8 I need to take breaks but since I stopped smoking I remain mostly at my desk.

Work i9 I want to be flexible in the choice of my work environment but accordant

Conditions company policies are required for that.

i10 I need to write in proper Romanian but the default English keyboards come without diacritics.

Personal i11 I would like to train general skills but the company does not foster it.

Develop- $\quad 112$ I would like to learn on my own but there is no dedicated eLearning content ment (e.g., video tutorials, interactive materials).

Personali- i13 I want an always visible external memory resource for frequently needed zation information (e.g., important deadlines), but my current solution (i.e., post-its) is not reliable and cannot hold a lot of information.

i14 I want to work on my tasks in different contexts/environments but there is no seamless way of doing so.

Tools $\quad$ i15 I need to compile lists and make calculations but do it by hand because I lack the necessary computer skills (Excel).

i16 I plan my day on paper because I don't see the benefit of digital solutions.

Note. The insights were synthesized from the needs and frictions analysis and formulated from the perspective of a user. Quotation marks are used to indicate utterances that originated directly from participants.

Ranking of Feature Ideas. In Table 2 we present the top 10 feature ideas that resulted from the ideation workshop and the online prioritization survey. As can be seen from the list, some of the features obviously are more innovative than others. For example, the feature 'Private Digital Noteboard' (\#1) is certainly more new to the world than the feature 'Walking Break Scheduler' (\#9). By contrast, the 'Walking Break Scheduler' is certainly more feasible - that is, less complex and therefore easier to develop - than the 'Private Digital Noteboard'. Yet, both of these features are useful in the sense that they address a real need - supporting a healthy lifestyle and staying on top of things, respectively.

Table 2. The 10 highest ranked Feature Ideas

\begin{tabular}{lllll}
\hline$\#$ & Feature name & Feature description & \multicolumn{2}{c}{ NUF score } \\
& (ref. to insights) & & M & SD \\
\hline 1 & Private Digital & Always visible second screen at personal desk: & 23.90 & 3.78 \\
& Noteboard & - Urgent tasks are highlighted & & \\
& (i1, i2, i13) & - Tasks are clustered according to projects/teams & & \\
& & - Finished tasks can be crossed out & & \\
& & - To-Do's/notes can be sent to public noteboard & &
\end{tabular}


2 Cognitive train- A selection of serious games to train cognitive skills to $23.20 \quad 4.34$ ing games prevent mental decline with personalized training sessions.

(i7, i11)

3 Exercise A friendly exercise reminder:

Prompter and

Demonstrator

(i7, i11)

- Prompting physical/mental exercises through pop-ups

- Avatar might demonstrate exercises

- Connected to calendar to know about ongoing meetings/deadlines

4 Flexible Self-

Tutorials on how to use new software/tools:

Learning Mini-

Modules

- Ca. 15 min per session

- To be completed until a fixed date

(i3, i12, i15)

5 Public Digital Noteboard

Always visible second screen at a wall:

- see \#1 Private Digital Noteboard

- To-Do's/Notes can be sent to private noteboard

6 Knowledge base (i5)

Central internal knowledge base within organization:

- "in case of problem X, contact Mrs. Miller..."

- Wiki on frequent problems to post questions

7 Healthy Email Organized as e-learning content (e.g., Guidelines/tips on $21.30 \quad 6.04$ Mgmt (i4)

8 Digital Paper Calendar how to better cope with the email load).

(i6, i16)

Paper calendar capable of automatically digitizing hand- $21.00 \quad 4.90$ written notes:

- Digital paper or digital pen as input device

- Tagging system (e.g., offline with different stickers or directly on the tablet/PC)

9 Walking Break Walking time in nature as part of the daily schedule and 20.914 .66 Scheduler (i8) encouraged by various means (e.g., calendar reminders, pop-ups...).

10 Remote Access A cross-platform tool to support task portability via secure $20.40 \quad 5.06$ $(\mathrm{i} 9, \mathrm{i14}) \quad$ remote access to company resources (i.e., files, software...).

Example Scenario and Mockup. We selected the Private Digital Noteboard (\#1) and the Digital Paper Calendar (\#8) for prototyping (see Tab. 2 above), resulting in the following scenario and mockup that combined both of these feature ideas (see below and Fig. 3).

Paul, a 55+ office worker, and his younger colleague Rachel work in the same building but on different floors. Paul needs to schedule a meeting with Rachel. Thus, he opens his Digital Paper Calendar to display her shared calendar. He sees an empty slot and writes down the following note with a smart pen on the 10 a.m. line: "Update on concept draft for BigHealth Inc. with Rachel". The Digital Paper Calendar interprets his hand-writing and suggests sending an invitation to Rachel. Paul confirms and a message is sent. Rachel responds via her Outlook calendar and suggests to meet an hour later at 11 a.m. Paul sees her request as a notifica- 
tion on his Private Digital Noteboard that he uses for displaying tasks and to-do's. He confirms the new time by touching the "accept" button on the display. He then also changes the time in the Digital Paper Calendar by simply drawing an arrow with his smart pen from the 10 a.m. to the 11 a.m. line.

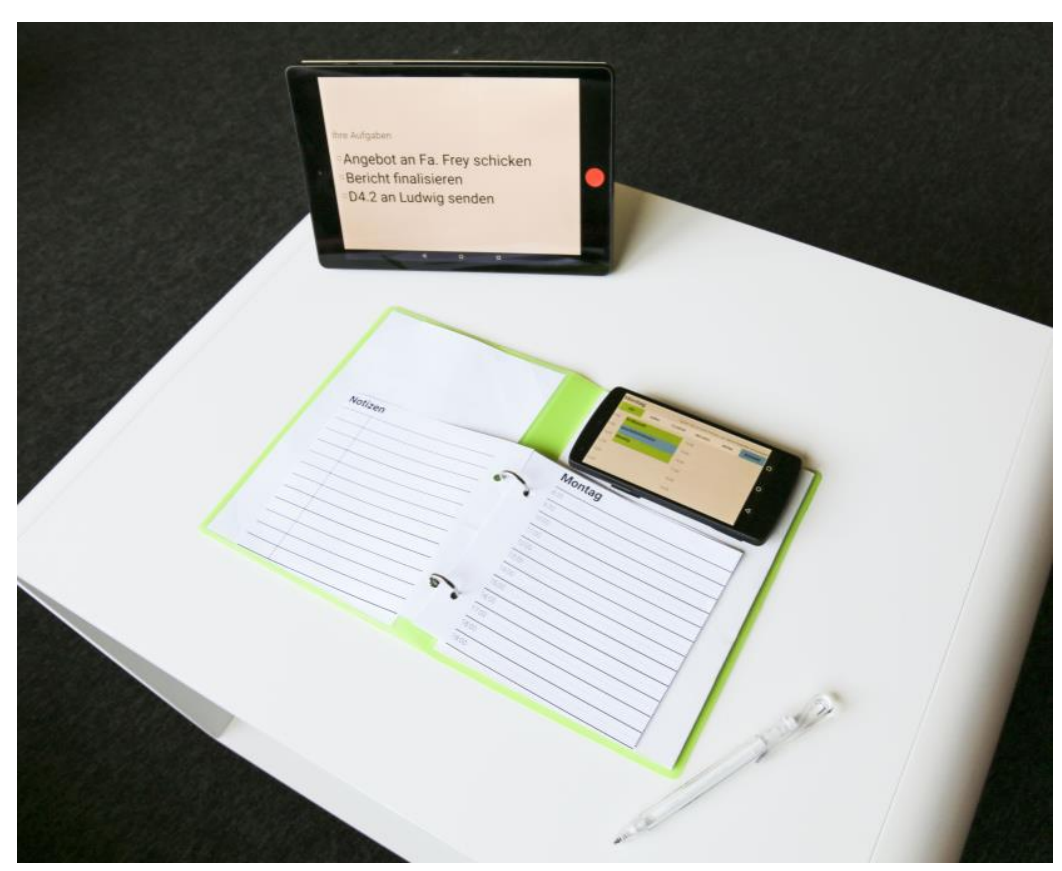

Figure 3. A mockup representing the Digital Paper Calendar and the Private Digital Noteboard.

We developed our mockup to fit into typical workplace settings and to take advantage of people's existing and well-established mental models about paper and touch-screen based interactions. It can be used for organizing meetings, managing a list of to-do's, or simply for taking notes. The proposed concept, as illustrated in Figure 3, consists of a paper calendar with a touch display along with a tablet used as noteboard. By using page tracking mechanisms, the Digital Paper Calendar is aware of the analogue page that is seen by the user and provides digital information accordingly. The proposed combination of page tracking, pen and paper input, a digital display, and an additional private screen seamlessly integrates common behaviors and habits that are highly familiar to the target group of older knowledge workers. To simulate the page flipping mechanism in future user studies, we developed an application that allows for remotely switching screens in a Wizard of Oz setup [26], on both the Digital Paper Calendar and the Private Digital Noteboard. 


\section{$5 \quad$ Discussion and Conclusion}

A primary goal of this case study was to map the contexts and environments of older knowledge workers in order to gain bottom-up insights that can support the ideation, design, and development of features for a smart work environment. In line with this goal, we followed a comprehensive multi-method approach, combining contextual interviews and observations, an analysis of needs and frictions for deriving insights, an ideation workshop for eliciting potential features, and an online survey among experts for evaluating the feature ideas on the dimensions of newness, usefulness, and feasibility. We want to emphasize that this list is not intended to be prescriptive or followed blindly but to serve as a basis for further specifications in the design and development of a smart work environment that caters specifically to the needs of older workers. Thus, its main value lies in providing food for thought to all project stakeholders and to inform rather than to enforce the decision on which features to select for further development. In our case, we used the list to select two feature ideas that we developed into a scenario and a mockup. This helped us to communicate the overall concept to future users and to gather feedback at an early stage.

The main contribution of this case study is the successful application of the compiled multi-method approach. Following this comprehensive approach, we were able not only to gain a rich understanding of the work realities and contexts of older computer workers, as is typical of ethnographically-inspired approaches in general (cf., [16]), but to transform that understanding into a concrete set of prioritized feature ideas that can form the basis for prototyping selected features. In the following, we briefly reflect on our experiences for each of the phases:

1. Contextual interviews and observations: using a smartphone camera rather than a dedicated camera to record turned out to be the right choice. Participants quickly forgot about the presence of the camera, which in our view helped to create a more natural setting. As a limitation we think it would have been useful to visit each participant not just once but more frequently, to align it more with the tradition in Corealization that emphasizes the importance of a long-term engagement between developers and users [18].

2. From needs and frictions to insights: we followed a practical approach in transcribing the contextual interviews and observations, which put emphasis chiefly on what was said rather than how it was said (as might be of interest from a more sociological perspective). This turned out to be sufficient for the purposes of our analysis that was focused on identifying needs and frictions.

3. Deriving feature ideas in an ideation workshop: a positive element of the workshop was the small number of people that sat at each table (three to four) that allowed for an active involvement of each participant. As a negative element, we noticed that having nine or ten insights per table was a bit overwhelming. We think that the number of insights discussed at each table can be reduced to around five.

4. Prioritizing feature ideas in an online survey: from our experience, it was a good choice to separate the prioritization of the feature ideas from the ideation workshop 
to prevent groupthink effects. However, if a 'safe environment' can be created during the workshop, then this phase might be merged with the previous one.

5. Prototyping of feature ideas: based on the prioritized feature ideas, we developed a scenario and a mockup. Such early prototypes are a fruitful way to communicate design decisions to the development team and to potential users. In addition to discussing the basic concept, they also provide input for discussions on details (e.g., particular functionalities, form factor, etc.).

To conclude, other than many ethnographic approaches that require considerable efforts in time and resources, our multi-method approach serves as a comprehensive, fairly easy to implement and efficient means of informing the design and development process, based on continuous direct involvement of users and other stakeholders in the design process. A key benefit of the approach is that the different phases efficiently combine to arrive at a concrete outcome, a set of prioritized feature ideas. Such an empirically well-founded prioritization can support designers and developers in selecting the most promising ideas for further development and prototyping. Future research may investigate how this holistic approach can be further streamlined to reduce costs and maximize the benefits for designers and developers of smart work place technology.

\section{Acknowledgments}

This work has been partly funded by the European Ambient Assisted Living Joint Programme and the National Funding Agencies from Austria, Denmark, Germany, Netherlands, Romania, and Switzerland: PEARL (AAL-2013-6-091).

\section{References}

1. Eurofound: Sustainable work and the ageing workforce. Publications Office of the European Union, Luxembourg (2012)

2. OECD: Live Longer, Work Longer. OECD Publishing, Paris (2006)

3. Roundtree, L.: The aging workforce: exploring the impact on business strategy. Boston College Center for Work \& Family: Executive Briefing Series (2004) 4. Gobel, C., Zwick, T.: Are personnel measures effective in increasing productivity of old workers? Labour Econ 22, 80-93 (2013)

5. van Dalen, H.P., Henkens, K., Schippers, J.: How do employers cope with an ageing workforce? Views from employers and employees. Demogr Res 22, 1015$1036(2010)$

6. Bobeth, J., Deutsch, S., Schmehl, S., Tscheligi, M.: Facing the user heterogeneity when designing touch interfaces for older adults: a representative personas approach. NordiCHI 2012, Copenhagen, Denmark (2012)

7 Wood, E.: Use of computer input devices by older adults. J Appl Gerontol 24, 419-438 (2005) 
8. Bobeth, J., Gattol, V., Meyer, I., Müller, S., Soldatos, J., Egger, S., Busch, M., Tscheligi, M.: Platform for Ergonomic and Motivating ICT-based Age-Friendly Workplaces. Workshop on Human Work Interaction Design for Pervasive and Smart Workplaces at NordiCHI 2014, Helsinki, Finland (2014)

9. Vicente, K.J.: HCI in the global knowledge-based economy: designing to support worker adaptation. ACM Trans. Comput.-Hum. Interact. 7, 263-280 (2000)

10. Eom, S.-J., Choi, N.-B., Sung, W.: The use of smart work in Korea: who and for what? Proceedings of the 15th Annual International Conference on Digital Government Research, pp. 253-262. ACM, Aguascalientes, Mexico (2014)

11. Stawarz, K., Cox, A.L., Bird, J., Benedyk, R.: "I'd sit at home and do work emails": how tablets affect the work-life balance of office workers. CHI '13 Extended Abstracts on Human Factors in Computing Systems, pp. 1383-1388. ACM, Paris, France (2013)

12. Greene, C., Myerson, J.: Space for thought: designing for knowledge workers. Facilities 29, 19-30 (2011)

13. Clemmensen, T.: A Human Work Interaction Design (HWID) case study in e-government and public information systems. International Journal of Public Information Systems 3, 105-113 (2011)

14. Beyer, H., Holtzblatt, K.: Contextual Design: Defining Customer-centered Systems. Morgan Kaufmann (1998)

15. Cau-Bareille, D., Gaudart, C., Delgoulet, C.: Training, age and technological change: Difficulties associated with age, the design of tools, and the organization of work. Work 41, 127-141 (2012)

16. Leonard, D., Rayport, J.F.: Spark innovation through empathic design. Harvard Business Review 102-113 (1997)

17. Crabtree, A., Rouncefield, M., Tolmie, P.: Doing design ethnography. Springer, London (2012)

18. Hartswood, M., Procter, R., Slack, R., Voß, A., Büscher, M., Rouncefield, M., Rouchy, P.: Co-realization: Toward a principled synthesis of ethnomethodology and participatory design. Resources, Co-Evolution and Artifacts, pp. 59-94. Springer London (2008)

19. Blomberg, J., Karasti, H.: Reflections on 25 Years of Ethnography in CSCW. Comput Supp Coop W J 22, 373-423 (2013)

20. Halse, J., Brandt, E., Clark, B., Binder, T. (eds.): Rehearsing the Future. The Danish Design School Press, København (2010)

21. Brown, J., Isaacs, D.: The World Café: Shaping our futures through conversations that matter. Berrett-Koehler Publishers (2005)

22. Gray, D., Brown, S., Macanufo, J.: Gamestorming: A Playbook for Innovators, Rulebreakers, and Changemakers. O'Reilly Media, Inc. (2010)

23. Carroll, J.M.: Five reasons for scenario-based design. Interacting with Computers 13, 43-60 (2000)

24. Alexander, I.F., Maiden, N.: Scenarios, stories, use cases: through the systems development life-cycle. Wiley (2005) 
25. Houde, S., Hill, C.: What do prototypes prototype? In: Helander, M., Landauer, T., Prabhu, P. (eds.) Handbook of Human-Computer Interaction. Elsevier Science B. V., Amsterdam (1997)

26. Kelley, J.F.: An empirical methodology for writing user-friendly natural language computer applications. Proceedings of the SIGCHI Conference on Human Factors in Computing Systems, pp. 193-196. ACM, Boston, Massachusetts, USA (1983) 